\title{
Enhancing Affective Awareness of DisAbility through Shared Learning in a Social Work Classroom: A Collaborative Project
}

\author{
Randy Johner \\ Faculty of Social Work, University of Regina, Regina, Canada \\ Email:Randy.johner@uregina.ca
}

How to cite this paper: Johner, R. (2016). Enhancing Affective Awareness of DisAbility through Shared Learning in a Social Work Classroom: A Collaborative Project. Creative Education, 7, 2121-2140. http://dx.doi.org/10.4236/ce.2016.715211

Received: July 8, 2016

Accepted: September 16, 2016

Published: September 19, 2016

Copyright $\odot 2016$ by author and Scientific Research Publishing Inc.

This work is licensed under the Creative Commons Attribution International License (CC BY 4.0).

http://creativecommons.org/licenses/by/4.0/

\section{(c) (i) Open Access}

\begin{abstract}
This article describes a small collaborative social work classroom project that included mentoring partnerships between community members with disAbilities and a university class of undergraduate social work students that focused on increasing affective awareness with regard to their understanding of disAbility or diverse abilities and comfort levels in working with people with disAbilities. This project was grounded in critical disability studies theory that examines powerlessness, context, social values, and language. Through qualitative analysis of data that was comprised of student assigned reflective ruminations, personal interviews with community partners, participant observations and reflective journaling, project findings indicated that students' experiences in the collaborative project had a positive impact on their understanding(s) of diverse abilities and comfort levels in working with people with disAbilities. Project recommendations include continued exploration of the pedagogical method in this project in order to support student learning outcomes in pre-service social work students, other health care pre-service students such as those in Education, Medicine, and Nursing and those students in interdisciplinary health-care service programs; and that further research is needed that examines diverse pedagogical methods that consider collaborative teaching methods that includes people with disAbilities. Continued classroom efforts are needed to assist pre-service social work students to support their understanding of the disability experience, and through that understanding, enhance their comfort levels in working with people with disAbilities; embracing the disability experience as an integral aspect of the human condition.
\end{abstract}

\section{Keywords}

Disability, Social Work Education, Community-Orientated Pedagogy, Critical

Disability Studies, Pre-Service University Students, Affective Awareness 


\section{Introduction}

This article describes a small collaborative project in a university social work classroom that had a positive impact on student affective learning about disAbility and inclusion. The social work undergraduate course was "Social Work \& disAbility Issues" that I taught at a Canadian mid-sized comprehensive university in the fall of 2012. Community members with intellectual and/or complex physical disAbilities as disAbility experts with lived experience of disability taught and mentored pre-service social work students in the classroom. A critical conscious lens that recognizes the barriers, assumptions and social political factors that deny people with disAbilities full societal inclusion and a shared teaching and learning approach informed the methodology of the collaborative project. Data collection included a qualitative questionnaire (pre and post introduction of teachers/mentors in the classroom), participant observation, reflective journal, assignments, and verbal/written comments about the project experience from students, mentors and supporters. In this article, the definition of "disability" is understood, "as experiences from attitudinal and environmental (structural) barriers that result in exclusion from participation because of bodily differences or body forms" (Stienstra, 2012) and as a process of meaning-making that takes place somewhere and is done by somebody (Titchkosky, 2007: p. 12).

Prior to describing this project, I will provide a brief overview of some of the literature that currently pertains to a lack of disability in social work curriculum and the presence (or lack of) of disabled professors in the classroom. I will then provide brief descriptions of a critical conscious lens (critical disability studies), affective learning and a shared teaching and learning approach in relation to disability that informed the development of this project. Lastly, I will give an overview of the social work class syllabus that included the collaborative class project, give a detailed description of the class project (also a research project), including its initial planning and development, class and mentor demographics, and findings from the class project data. When presenting findings from the class project data, I will include the voices of some of the social work students, as well as those of some of the mentors and a support person who were the disAbility experts in this project. Space does not allow me to include all of the voices but my intention as I describe this project is to instil in the reader a sense that everyone's voice was integral to the development and outcome of this project. In conclusion, I will share what I learnt from this class project about myself as an educator in a project that created a place of transition whereby reflexive thought, feeling and action directed towards difference and inclusion was mainstream, rather than something to be examined as outside of the "natural part of the human experience" (Ferguson \& Nusbaum, 2012: p. 76).

\section{Theoretical Background}

\subsection{Absence of Disability in Social Work}

Based on the findings that there are few schools of social work in Canada that have courses specifically about disability and disability issues or hire faculty with research 
and academic interests in disability studies, MacDonald, Dunn and Hanes (2003) found that most social workers have little to no understanding of disability issues although many social workers will work with people with disAbilities (as cited in Dunn, Hanes, Hardie and MacDonald, 2006: p. 2). In addition, a survey of 491 schools of social work in the United States and 32 schools of social work in Canada revealed minimal disability curricula and generally an overall lack of disability content in social work education (Jurkowski \& Welsch, 2002). However, a collaborative study between two Canadian universities, investigated the perspectives of upper year undergraduate medical students with regard to their academic preparation in working with people with intellectual disabilities upon graduation and found that there was wide spread support from those undergraduates surveyed that more training in intellectual development was needed (Burge, Ouellette-Kunz, Issacs, \& Lunsky, 2008: p. 570). Evidence from this study (Burge et al., 2008) strongly suggests that curriculum enhancements should include training in intellectual disability in undergraduate medical education programs. Once can further speculate from the evidence gathered in Burge et al.'s (2008) study that all professional educational programs, including social work, should enhance their curriculums with specific content and training in disabilities.

\subsection{Professors with Disabilities}

Studies that have examined undergraduate students, including social work undergraduates' attitudes towards disability have found that those students who had a professor with a disAbility had more positive attitudes about disability than those students who had a professor without a disability (Hayashi \& May, 2011; Shannon, Schoen, \& Tansey, 2009). Based on their findings, Shannon et al. (2009) suggested that the promotion of contact with persons with disAbilities who are in an academic leadership role could be an important aspect to the development of positive attitudes towards the condition of disability among undergraduate students. Dunn, Hanes, Hardie and MacDonald (2006) suggest that social work faculty members with disAbilities can “...speak from their location, using their own experiences as teaching moments" (p. 15). Further to this, Dunn et al. (2006) study findings indicated that Canadian social work students with disAbilities "...need to see a mirrored reflection of themselves in faculty and staff in order to be reflective of acceptance, provide knowledge and mentoring resources as well as act to 'normalize' their situation within schools of social work" (p. 14). Lastly, Dunn et al. (2006) state that there are few Schools of Social Work in Canada that offer courses on social work and people with disAbilities let alone have a "speciality" in disability (p. 2).

Because I have been a person with a disAbility since birth, I am privileged to have the lived experience of disAbility that individuals without disAbilities do not have. What I have come to know is that without the lived experience of disAbility there is a (dis)connection and a lack of awareness for human differences and diverse abilities when experiencing life through a lens of ableism. This is troubling for me from a number of perspectives: as a person with a disAbility, as a social work educator and as a social worker. As the experience of disablement is different for everyone, I can only share my 
experience of disablement as confined within mainstream taken-for-granted parameters of "normalcy" (Titchkosky, 2009). Yes, there are commonalities for persons with disAbilities to exclusionary realities such as access to the environment, material resources, relationship opportunities and stigmatization that unite disabled social identities but the uniqueness of the experience of disability for individuals must not be smothered under a public umbrella of universalism (Titchkosky, 2009).

\subsection{Critical Disability Theory}

Studies that have examined undergraduate students, including social work undergraduates' attitudes towards disability have found that those students who had a professor with a disAbility had more positive attitudes about disability than those students who had a professor without a disability (Hayashi \& May, 2011; Shannon, Schoen, \& Tansey, 2009). Based on their findings, Shannon et al. (2009) suggested that the promotion of contact with persons with disAbilities who are in an academic leadership role could be an important aspect to the development of positive attitudes towards the condition of disability among undergraduate students. Dunn, Hanes, Hardie and MacDonald (2006) suggest that social work faculty members with disabilities can "...speak from their location, using their own experiences as teaching moments" (p. 15). Further to this, Dunn et al. (2006) study findings indicated that Canadian social work students with disAbilities "...need to see a mirrored reflection of themselves in faculty and staff in order to be reflective of acceptance, provide knowledge and mentoring resources as well as act to 'normalize' their situation within schools of social work" (p. 14). Lastly, Dunn et al. (2006) state that there are few Schools of Social Work in Canada that offer courses on social work and people with disAbilities let alone have a "speciality" in disability (p. 2).

\subsection{Shared Teaching \& Learning Approach to Affective Learning}

In the collaborative class project that is the focus of this paper, students were asked to work on developing a deeper awareness than they currently had with regard to their personal (values, beliefs, emotions, impact on practice) and professional/institutional (language, values) attitudes; these attitudes were the primary focal points of the affective learning objectives for the students in this collaborative class project. Of the three domains of learning (i.e. cognitive, behavioral and affective), affective learning has been described as the most complex of the three domains as student's beliefs, attitudes, impressions, desires, feelings, preferences and interests are focal points (Allen \& Friedman, 2010; Friedman, 2008). Allen and Friedman (2010) state that generally social work educators tend to rely on cognitive learning strategies to stress key components of the affective domain such as self-awareness, values, attitudes and ethics for numerous reasons: 1) The affective domain is poorly conceptualized, highly individualized and difficult to directly assess; 2) The prevalence of educators towards standardized testing and mastery learning; and 3) The domain of affective learning incorporates the domains of cognitive and behavioral learning.

According to Bunch and Valeo (2004) theories of social learning and social referencing 
promote the notion that students without disAbilities learn from others how to interact with individuals with disAbilities. In addition, contact theory suggests that through certain types of contact, prejudice towards a non-dominant group, such as those with disAbilities, will be diminished, and a path towards a more inclusive society can emerge. Silvers and Francis (2005) also posit that insights gained from social contract theory lie with recognizing the importance of respecting all individuals conceptions of their value to society; thus contract theory framed in terms of building trust relationships among individuals (i.e. with and without disAbilities) will foster inclusiveness (acceptance) and respect.

As an educator, it is important to discover how best to address affective learning in a class about disAbility and inclusion, given the current literature that suggests that all people with and without disAbilities, can learn about acceptance and inclusion from one another in meaningful ways. During a conversation with the Co-ordinator of the Campus for All program (an inclusive post-secondary program) at the university, we came to the conclusion that incorporating a project as part of the class content that consisted of inviting persons with disAbilities to mentor/teach the students from their knowledge and experiences about disAbility and inclusion could be a meaningful learning experience for everyone. Mentors with disAbilities would be given "voice", and would have a key role in the learning experience with groups of students; and the students would be able to interact and learn about disAbility and inclusion in meaningful ways particularly from the perspective of affective learning.

An examination of the literature did not result in examples of research that described the development of a collaborative partnership in order to facilitate persons with disAbilities teaching social work students in a post-secondary classroom setting. According to Mackelprang (2010), "within academia, social work education and disability studies have little in common" (p. 94). In the literature, there are a few examples of medical schools developing disability curriculum that have both acknowledged the expertise of disabled persons as experts living with disability and invited disabled persons to teach in the classroom (Kahn, 2003; Minihan et al., 2004; Wells, Byron, McMullen, \& Birchall, 2002).

However, studies that have explored the behavioral intentions of students towards their peers with an intellectual and/or physical disAbility have found that there needs to be meaningful respectful interactions between students with and without disAbilities in order to promote inclusion from the perspective of acceptance, promotion of human rights, accommodation and accessibility and citizenship. For example, Brown, Kuntz, Ltsaght, and Burge (2011) compared the behavioral intentions of 319, Grade 9 and Grade 12 Canadian high school students towards peers with intellectual and/or physical disAbilities, and explored the reasons for these behavioral intentions. The students completed a questionnaire and also responded to open-ended questions about completing a class assignment or engaging in a social activity with peers who had an intellectual and/or physical disAbility. Findings from the questionnaire indicated that there were a significant lower proportion of individuals who were willing to engage in an 
activity with someone with an intellectual disAbility versus a physical disAbility. Brown et al. (2011) suggest that that their study findings point to the reluctance of the high school students to interact with people with disAbilities because of their apparent discomfort in not providing "socially acceptable" responses (p. 330). The explanation for students' discomfort may be linked to the perceived dissimilarity of people with and without disAbilities (Brown et al., 2011). Because of these study findings (Brown et al. 2011), the authors suggest that there is a need to support meaningful interactions (equal-status) or tasks in which each person with and without a disAbility has a key role. These research findings corroborate with earlier study findings that found most interaction between students with and without disAbilities was likely to be uni-directional with the students without disAbilities assuming an educative role towards the students with a disAbility (Place \& Hodge, 2001).

As an example of persons with disAbilities utilizing their expertise to teach undergraduate students about disability, at the Bristol Medical School in Britain, persons with and without disAbilities formed a committee that developed a core disability curriculum based on the social model of disability of attitudes, knowledge and skills deemed necessary for medical students to acquire (Wells, Bryon, McMullen, \& Birchall, 2002). The social model of disability focuses on the attitudinal and environmental barriers that disabled people face in their daily lives. In addition, the social model of disability critiques the idea of normality with regard to average human functioning (Terzi, 2009). Although there is some debate around this critique of normality because needs and services are determined based on "abnormal functioning" from a pre-defined norm (Terzi, 2009: p. 90 as cited in Johner, 2013), Morris (1991) asserts that people with disAbilities do not reject the differences that are important to their identity but that they do reject the meanings that the non-disabled world attaches to disability (p. 15). Within this core disability curriculum thirteen topic areas within the curriculum were deemed essential and six of those involved affective learning, specifically focusing on attitudes.

Attitudes that were considered essential to the Bristol Medical School disability curriculum included an awareness of one's own attitudes (values, stigma, assumptions, reflective practice), societal attitudes (values and language), institutional (professional practice should be empowering not disempowering), partnership (the person with disAbilitiesas the expert), carers (importance), and health workers (importance of other professionals). The curriculum included individuals living with diverse hearing, speaking, visual, and learning conditions who led small workshops with the medical students. Medical educators realized that persons with disAbilities must be introduced as a "teacher" in the classroom, as only then will expertise of people with disAbilities and their active collaboration with students be fully realized (Minihan et al., 2004; Wells et al., 2002).

\section{Collaborative Class Project: A Description}

The class that included the collaborative research project (mentors with disAbilities, to teach social work students about disAbility and inclusion), is called, Social Work \& 
disAbilities Issues. This class is an upper level undergraduate social work class with 35 students. It is an elective class, rather than a required class. The description of the class project as well as descriptions of the mentors and their support persons (paid, voluntary or family members) follows this section. The class content for the first six weeks of the class included theoretical perspectives of a number of different models of disability, including the medical model, the charity model, the social model, and critical disability studies. For the first six weeks of the class (each class was two hours and 45 minutes long), the students and I discussed these various perspectives of disability, utilizing diverse mediums such as film, podcasts, digital stories, case studies, and readings to understand and reflect on these perspectives in relation to self and professional practice.

The last six weeks of the class were primarily devoted to creating a transitional space that would allow for reflexive understandings and awareness of diverse human differences and inclusion. The creation of this space of transition took place during the last hour of the class. The last hour was scheduled for mentors, student teams, and support persons to develop relationships and through the relationship building process, create a collaborative class project that explored disAbility and inclusion. The overall class goal was to unfetter the intellect from the common stereotype of disabled persons (Pfeiffer \& Yoshida, 1995). The overall affective learning objective was to increase awareness of one's own attitudes about disabled people.

Affective class learning objectives included the following: a growing awareness of the emotional and physical effects of societal exclusion upon disabled persons; a growing awareness of personal and professional responsibility to promote "abilities" and reject "othering" in order to promote inclusion and acceptance; and a growing awareness of acceptance and empowerment in teamwork that focuses on "ability" rather than "disability".

Class assignments included critical reflexive ruminations, a final exam comprised of one essay question and a collaborative class project. Students were asked to write four critical reflexive ruminations over the course of the term. The focus of change in critical reflection is the individual practitioner. In contrast, reflexivity focuses on change in the profession and in society. Reflexivity acknowledges and considers the importance of power not only at the micro level of self and in a practitioner's relationships with others, but also at the macro level, as it considers the role of power within society and the history of social work (Drolet, Clark, \& Allen, 2012: p. 146). Reflexive practitioners must commit to ongoing dialogue and deconstruction of "tacit, personal, professional or organizational knowledges" and their influences on social and political debate (Parken, 2010: p. 85) Reflexive practice calls for the possibility of multiple truths (as opposed to one "objective" truth) and the inclusion of a diversity of perspectives-in fact, it privileges voices from the margins or those excluded from the "expert" role (Bolzan, Heycox, \& Hughes, 2001). For each rumination, students were expected to address a specific issue linked to course content, readings/videos/and/or discussions. Students were also required to write a final exam for one hour in duration that consisted of one question that would be linked to their specific learning with their mentors. 
In addition, students were required to participate in the major collaborative project with mentors or disAbility experts who would teach, support and mentor social work student teams during the development and final presentation of the team workshops. Each disAbility expert worked with their student teams for 45 to 60 minutes for the last six weeks of the term. Each student team developed a 1/2 hour workshop titled, "What is disAbility?" for one of the following groups: children, teens, university students, parents, teachers, social workers, researchers, policy-makers or medical personnel. Students were able to choose any aspect of disAbility that they wished to share with others in order to address societal perceptions of "difference" or "other" based on ability. The goal of these workshops was to foster acceptance, inclusion and good citizenship. Workshops utilized diverse mediums such as role-plays, games, digital stories, music, photos, etc.

\section{Methodology}

Research ethics approval for the collaborative class project was obtained in order to be able to share project findings with others such as social work students and practitioners, educators and other health care professionals. The inclusion of experts with lived experiences of disAbility teaching in this class was a new initiative, and thus a "research" project deemed worthy of sharing. The sample was a purposive sample as included all of the students, mentors, and support persons in the class who volunteered to participate in the research. In this project, all persons (students $(\mathrm{n}=35)$, mentors $(\mathrm{n}=$ 6 ), and support persons $(\mathrm{n}=3)$ ) who participated in the class, volunteered to participate in the research project.

Data collection that specifically focused on the affective learning objectives consisted of the following methods: a short qualitative questionnaire that students answered prior to the mentors joining the classroom and answered again (the same qualitative questionnaire) one month after the mentors had been teaching their student teams, student written comments and assignments, as well as my participant observations and reflective journaling. The short qualitative questionnaire contained two questions that focused on defining disability and the comfort level with disability: 1) How do you define disAbility? and 2) On a scale of 1 - 10 with 1 being not at all and 10 being completely at ease: how would you rate your comfort level when interacting/spending time with people with disAbilities? Please Explain.

The choice of the word "comfort" used in this questionnaire was chosen because comfort relates to positive physical and emotional conditions and feelings, and the alleviation from stress that correlates well with the affective learning objectives for the course. The word, "comfort" is often present when discussing individual experiences. For example, research indicates that patients are much more likely to agree to have a medical student involved in their care and are more comfortable with their involvement in their care, if they have had prior experiences with medical students (Hartz \& Beal, 2000). Given these types of findings (Hartz \& Beal, 2000), it is feasible to anticipate that social work students who had prior experience with people with disAbilities would 
likely be more comfortable with these individuals than possibly those students who had no prior experience with people with disAbilities. A colleague distributed the call for volunteers, consent forms and questionnaires to the students in an attempt to address issues of coercion and power differentials associated with student and teacher relations in the classroom.

As previously stated, the sample for this project consisted of 35 students: there were 31 female students and four male students. Enrollment in social work classes at the university generally allows a maximum of 36 registrants. These students were $2^{\text {nd }}, 3^{\text {rd }}$ and $4^{\text {th }}$ year level social work students. All of the students with the exception of one were under thirty years of age. The majority of the students were between 19 and 25 years of age. There were five students with either a physical or learning disAbility (self-declared). Over half of the students had either worked with individuals with a disAbility and/or had a friend or a family member with a disAbility. There were five or six students in each team; with the inclusion of each team mentor (random assignment to teams), student teams were six or seven members in total.

The planning of this collaborative research project that included mentors with disAbilities comprised six months of preparatory work and dialogue with folks from the two inclusive post-secondary education programs at the university: Campus for All and Astonished! And the Astonished! Teaching and Learning Centre (A! TLC). A total of six mentors, disAbility experts, from these two inclusive university education programs volunteered to teach the undergraduate social work students. These two inclusive education programs were chosen as potential partners in this project because of established collegial relationships and program mandates to promote diverse abilities and inclusion.

Campus for All (CFA) is an Inclusive Post-Secondary Education (IPSE) that supports up to 12 students who have intellectual disabilities. There are no separate classes or curricula for CFA students. Students audit one class per semester. CFA students' attendance in classes is "participatory auditing"; as much as possible and is desired, students participate in all aspects of class. The Campus for All website indicates that eligibility to apply to Campus for All is based on: mature student status (22 years of age and over); an intellectual disability (self-declared); does not meet general university admission criteria; motivated to become a student at the university; curious and interested in learning; willingness to make Campus For All a priority for four years; has resources available to meet support requirements; and has the support and interest of friends/family/or others.

Astonished! Teaching and Learning Centre (A! TLC) is a place of learning where young adults with complex physical disAbilities become Student Researchers. According to the website, Student Researchers' unique opportunities are designed around their particular strengths, dreams, and needs. "Astonished! Staff work to support each Student Researcher as they each determine and navigate a PATH (Planning Alternative Futures with Hope) unique to them. In the A! TLC, Student Researchers are leaders and work with faculty, students, and the wider community in research, learning, and 
teaching about inclusion".

In total six mentors volunteered to work with the social work students. The Campus for All (CFA) Co-ordinator was responsible for recruiting five of the mentors for the social work student teams. Potential mentors needed to possess some confidence in communicating/creating a dialogue in groups and working with a group, had to be comfortable in communicating about their disAbilities and (lack of) inclusion, and have a desire to be a teacher and/or to positively impact others or society in some way about disAbility and inclusion. Banner and Cannon (1999) suggest that teachers must convey the love of learning to others; and that with complete mastery of the subject matter (i.e. experiences living with conditions of disability) that this energy and excitement in the subject area will be imparted to their students. With the exception of one mentor, George, four of the mentors were current or former CFA students; George is the husband of Cara (pseudonyms used for all persons who were mentors or supporters of mentors) a (former CFA student). Three of these five mentors, including George and Cara were wheelchair users. The age range of these mentors, ranged between 22 and 42 years of age.

The sixth mentor for the social work student teams was a Student Researcher from the Astonished! Teaching and Learning Centre (A! TLC) at the University of Regina. Jennifer was 23 years of age, a wheelchair user and lives with a diverse form communication that does not include spoken words. A support person, Rose, navigated Jennifer's wheelchair, met any personal care needs, and assisted the social work students in developing a relationship with Jennifer. Rose, who knew Jennifer from birth, advised the students that: the physical body is just a vessel, and that as long as Jennifer can understand, she can interact and build relationships with others. Although Rose was Jennifer's auditory voice, Jennifer is very expressive, and communicates what she is thinking with facial and body expressions. As language is often perceived to be of key importance "...both in having a voice and gaining access to social and political debate" (Pound \& Hewitt, as cited in Swain, French, Barnes, \& Thomas, 2004: p. 161), Rose was extremely instrumental in helping to bridge perceived language/communication challenges that the social work students felt with Jennifer in the first few classes. Most of Jennifer's team members did not have prior experience in communicating with someone with a diverse form of communication. As stated previously, just as with CFA mentors, Jennifer, from $A$ ! TLC had to have some confidence in communicating/creating a dialogue in groups and working with a group, had to be comfortable in communicating about their disabilities and (lack of) inclusion, and have a desire to be a teacher and/or to positively impact others or society in some way about disAbility and inclusion.

Before the mentors arrive, the classroom space must be accessible and inclusive; thus, many tables and chairs must be moved against walls so that every mentor who utilizes a chair for mobility will feel welcome and can navigate comfortably within the classroom. The first meeting is initially full of apprehension; the students and mentors express feelings of nervousness due to meeting new people and working with them in new roles 
(mentor/mentee). The first session is devoted to getting to know one another, and in developing a comfort level with each other. From my observations, everyone gave their full attention to the development of meaningful relationships with intense energy permeating the room. After the initial session, each time the mentors join the classroom, there is much activity interspersed with thoughtful moments and what sounds like hilarious laughter among teams and between members. Teams spread out to all corners of the room; with some teams going to other areas of the university as they complete their team work (i.e. video-taping an interview, creating a digital story, etc.). Teams also chose to meet outside of regular class time, either off campus or on campus to work on projects. Some teams also chose to engage in sport or social activities in the evenings or on weekends that are linked to their projects in the community.

\section{Findings \& Discussion}

A critical disability lens means “...being able to see beyond the status quo, looking beyond symptoms and labels, seeing the reality of people's situations, and understanding how they are linked to attitudes, policies, and systems" (Lord \& Hutchson, 2007: p. 14). A critical disability lens challenges current understandings, labels and stereotypical assumptions about disability and disabled lives, particularly in relation to the assumptions built into the medical model of disability. It is important that social work challenge the medical model of disability (the problem is located within the person), and not in the environment (physical/attitudinal), such as understood in the social model of disability; the medical model of disability is currently the dominant model of disability prevalent in social work and other health care services. Social workers must learn about living with disAbilities not from medical experts but from people with disAbilities who are disAbility experts (Hiranandani, 2005). Social workers must move beyond medical labels and stereotypic notions of disability by listening to people with disAbilities who can teach all health care professionals about disAbility and disabled lives. If health care professionals continue to cling to medical labels and assumptions of limitations based solely on functional capacities, they have not heard the "voices" of those with disAbilities, and will continue to dis-empowered others, reinforce normalcy and ableism, and ultimately will fail in the pursuit of an inclusive and just society.

In this class project, students were invited to develop a deeper awareness than they currently had with regard to their personal (values, beliefs, emotions, impact on practice) and professional/institutional (language, values) attitudes through the mentorship of persons with disabilities. As previously stated, the overall class goal was to unfetter the intellect from the common stereotype of persons with disAbilities (Pfeiffer \& Yoshida, 1995). And, the overall affective learning objective of the class project was to increase awareness of one's own attitudes about disabled people. Theories of social learning and social referencing (Bunch \& Valeo, 2004) as well as contract theory (Silvers \& Francis, 2005), promote the notion that meaningful contact between individuals such as students with and without disAbilities can promote greater understanding of disabilities, as well as potentially create pathways to a more inclusive society. Based on these 
theories, and the ethical responsibility of social workers to pursue a just and an inclusive society, particularly for marginalized populations such as individuals with disAbilities, as an educator, I felt that it was imperative that people with disAbilities be given a teaching role with students in a social work class that focused specifically on disAbilities. The success of this collaborative class project can be ascertained in several ways: 1 ) Did the students develop a deeper awareness (e.g. were comfort levels positively impacted) with regard to their personal and professional attitudes towards people with disabilities, and 2) Was the teacher role for persons with disAbilities a meaningful experience for everyone (students and mentors?) In order to shed some light on these questions, I will share some of the collaborative class project findings from the questionnaires that were given to the students, some of the student reflective journal entries (one of the class assignments), and lastly will share some voices from some of the mentors as well as from Rose, a mentor supporter during the class.

Prior to the mentors joining the classroom, the overall qualitative scores for the student pre-test question, on a scale of 1 - 10 with 1 being not at all and 10 being completely at ease: how would you rate your comfort level when interacting/spending time with people with disAbilities? Please explain, was 7.4 out of 10. Four weeks after the mentors had joined the classroom, the overall qualitative scores for the student posttest question, on a scale of $1-10$ with 1 being not at all and 10 being completely at ease: how would you rate your comfort level when interacting/spending time with people with disAbilities? Please explain, was 8.1 out of 10 . As this is a qualitative study with a small purposeful sample, determination of statistically significance difference between the pre and post test scores is not possible, nor desired. Although there were notable visual changes between the pre and post test scores, the student voices speak to the "significance" or impact on their comfort levels from their experiences when working with persons with disAbilities in the collaborative project in the classroom; the mentor and support person voices attest to the meaning of the experience for themselves.

Student Voices: Pre and Post Test. Following are several student explanations pre and post mentor involvement that explain the differences in how these specific students rated their "comfort" level when interacting/working with people with disAbilities. Student A rated her/himself $2 / 10$ in the pre-mentor comfort level and $7 / 10$ in the working with mentor comfort level. Pretest: I have honestly had very little experience with people with disabilities. I often find myself uncomfortable; I don't know what to say or do. I feel as though I am walking on thin ice, never knowing or wanting to upset or embarrass them. I wonder to what degree I should or shouldn't acknowledge the disability? Is it ok if I ask questions? What sort of expectations I should have of them. Posttest: I think I have learned a lot from the mentors in this class and without them I would not have learned what I did. Our mentor has taught me that disability is not something to fear.

Student B rated her/himself $4 / 10$ in the pre-mentor comfort level and 7.5/10 in the working with mentor comfort level. Pretest: Currently I do not spend time with individuals with disabilities. My discomfort doesn't come from unease with another's 
disability but rather has more to do with not wanting to offend them or make them feel bad by doing or saying the wrong thing. Posttest: Having a chance to interact with people who have disabilities has had the greatest impact on me in terms of normalizing disability \& increasing my comfort level. I see it more as just one small aspect of the person as a whole. I look at their eyes before the "disability".

Student $C$ rated her/himself $8 / 10$ in the pre-mentor comfort level and 9/10 in the working with mentor comfort level. Pretest: I think I am quite comfortable when interacting with people with disabilities because I have a disability myself. However, even though I have personal experience, I wouldn't say that I am completely comfortable. This is because sometimes I don't know what to say or do when interacting with people with disabilities. Post-test: I feel more at ease after spending time with my mentor in a social work disability class. However, I m still not $100 \%$ comfortable because sometimes I still don't know what to do or say.

And lastly, student D rated her/himself $9 / 10$ in the pre-mentor comfort level and dropped to $7 / 10$ in the working with mentor comfort level. Pretest: I grew up with a brother who had severe $C P$ [cerebral palsy] and other disabilities. I am involved with a disabled sailing program and try to keep an open mind. Posttest: Depending on the severity of the disability $P$ ve found my level of comfort changes. I would say overall I would be at a 7 for all ranges of disability after having learned more about the possible range of special needs.

The language that students used to define disability in the pre mentor comfort level also changed when defining disability in the working with mentor comfort level test rating with definitions moving from disability within the individual to societal barriers to questioning why "reality" for many disabled persons is socially exclusive rather than socially inclusive. For example, student E, pre mentor comfort level (8.0/10) stated: $I$ can define disability as having or feeling like there is something holding you back from society that is "not normal"; such as anything from-learning, cognitive, physical, cultural; it is just not physical. After having worked with her/his mentor, student E rated his/her comfort level as 8.5/10 and stated: I see disability as when society does not accept what is different and make changes or does not allow there to be tools made available for people to create ability.

Another student F, pre mentor comfort level (6.5/10) stated: I actually don't [define disability]. I don't like the word \& refer to it as "different ability" because everyone is equal, just our abilities vary. The focus should not be on the "lack of ability" but rather the differences that we each have \& how we can learn from one another. After having worked with her/his mentor, student F rated his/her comfort level as 7.5/10 and stated: "although I have established a definition of being inclusive \& accepting", the more I hear, see \& read from various sources (mentor, society, journals, etc.) Disability is seen as "less than" and having something that makes you not able to do something. I really don't know how to look at disability any more. Do I view it the way I used to? Or do I adopt the view that everyone else seems to have? Mine appears to be a hope rather than what everyone else believes, which is "reality".... 
Third Reflexive Rumination Assignment. And lastly, student voices will be shared via the third reflexive rumination assignment that read as follows: This reflexive rumination will focus on connectivity-community-inclusivity. What have you learned from your mentor with regard to the three constructs: connectivity, community, inclusivity? How does your learning connect (or not) to any of the models (or a combination) of disability that have been discussed in class? Student G wrote (an excerpt): I honestly do not know where to begin in response to this question. My experience with George has been overwhelming and enlightening. Coming into this class I was very uneasy and afraid to work with people with disabilities... George taught me that the first step to working with individuals with disabilities is that they are the same as everyone else. They have ideas, priorities, concerns, and motivation and these are all very legitimate. Involving people with disabilities in discussion not only gets their perspective on the table, but it also gives them a sense of inclusion and empowerment, an opportunity to be part of something. George is a very knowledgeable person and spoke a great deal on how notions of connectivity, community, and inclusivity are all interconnected. When people with disabilities are included then they are able to connect with others and become part of the community.

Student $\mathrm{H}$ wrote (an excerpt): As I am writing this, I was about to say that we had gotten to know her [Joan] without attention to her special needs, however I think that would be untrue. Although we developed a relationship with her on a very personal level, Joan's special needs are very much a part of her and make up the person she is. When we asked if there was anything she would change about herself, she said "nothing", which I think is a very powerful thing.

Mentor voices: Joan. The Campus for All (CFA) co-ordinator asked mentors from the CFA program to consider the following questions. These are questions that the CFA co-ordinator felt would be applicable to the CFA mentors and their experiences in working with the social work students. Joan (former CFA student) wrote down her answers. Why is it important for students in the social work class to learn from you-a person with a disability? Because it is Good (when) you see someone now with a special needs out in the community-It helps you understand how hard it is for them to get around + live their life. How do you like being in the teaching role (for a change)? I really like it!) What have you learned from this experience? about yourself? about working together? Enjoy being back at $U$ of $R$-with students, I have more confidence, I feel proud to help others do well/ and so they can go to school too. Would you do this again? Yes! Absolutely—Love it! Very glad to be of help to others!

Mentor Voices: Cara (former CFA student) and her husband George shared their answers to the questions with me. I wrote down their answers as writing was challenging for them; we reviewed what I had written to make sure that I had written down exactly what they wanted to say. Why is it important for students in the social work class to learn from you - a person with a disability? Let's just say it will teach them about our disability that way if they encounter anyone with a disability they will already know. How do you like being in the teaching role (for a change)? I like it. Yah, it is 
because you are teaching about how it is like to be in a wheelchair all your life, so when the students are working with disabilities, they know how to understand them better. We run into social workers who don't know anything about disability, it is ridiculous. So now with this class, it will help people in the future. Thank you for having this class. They [the students] will have more understanding when they go into the field and won't be shy. What have you learned from this experience? about yourself? It is better to be on the opposite side-to be a teacher-it makes me understand more about what I have. Same with me-we are teaching from experience. We have been in chairs all our lives, we see things from disability. about working together? You don't know what they [the students] know and if they will work with you-it is a learning curve. Would you do this again? Yah, it is a good experience. You get to teach students about disabilities from a person who is disabled. Sometimes people make assumptions about people with disAbilities; they don't know about disability. Sometimes people are rude and just don't understand.

Support Voice Rose \& Mentee, Jennifer. "Jennifer enjoyed the class a lot, it was a learning experience for both the team and Jennifer, once the first class was over and the ice was broken things went well. We have always told Jennifer that there is something different about everyone and to never judge anyone for what they can or can't do. So when all the questions started I think she felt a little intimidated but it didn't take long for Jennifer to allow me to tell all the questions were on every aspect of her life there was no holding back. I think that even Jennifer learned a little more about herself and this is what makes her whom she is. By the end of the semester I feel that there was a better understanding of what Jennifer has to face on a day to day basis. We think it is very important that the students learn firsthand as they will be working in the community with a diverse amount of disAbilities and they will have an understanding of people that have different abilities. Jennifer came away from the class making a few really good friends that she still keeps in contact with on a weekly basis and realizing that she is a very strong person".

\section{Strengths/Limitations of the Study}

This small qualitative project included multiple data gathering strategies such as a qualitative questionnaire, student and mentor comments, student assignments, participant observations, and reflective journaling in order to ensure the trustworthiness of the research (Lincoln \& Goya, 1985). In addition, member checks were made with students, mentors, and support persons in order to confirm the accuracy of their statements and intent (did they say what they intended to say?). Thick descriptions of the data were presented in order to support the readers' understanding and researcher interpretation of the data (Amney, 2014). Lastly, the researcher's reflective journal serves as an audit trail that recounts the research project from inception through to data gathering and interpretation (Lincoln \& Goya, 1985). As with any qualitative research, the purpose of such work is not to generalize to a population as in quantitative research but to explore individual experiences (Vishnevsky \& Beanlands, 2004). The inability to 
generalize to a population is considered a limitation of the research. In addition, this research project is a cross-sectional research project that describes a particular project located within a specific time and place; thus rendering the findings specifically applicable to this project's context. Much more research is needed in order to substantiate this project's findings within similar as well as diverse contexts.

\section{Epilogue}

On November 5, 2012, I wrote in my journal: I noticed a lot more laughing at the end of the month-like the process had consumed the student teams, and I was on the peripheral edge-looking enviously in. It was almost as if the students wanted (needed?) to work together, their projects (creations) were consuming the class, there was a sense of patiently waiting (getting through?) the instructor guided to the mentorlstudent led projects. The energy was wonderful: totally consuming and all focussed. Since writing that journal entry, I have taught this class for four consecutive years, and the energy generated from this class once the mentors join us, continues to be wonderful, totally consuming and all focused. In addition, students from other faculties, such as Education and Kinesiology \& Health Studies, now register for this social work class.

The number of mentors in the classroom has increased from six (initial class) to ten mentors, with each mentor supporting two to four students. We have more mentors and more mentor supporters because the social work students from the first class felt that the teams should be smaller, and thus more manageable in terms of working together, and coordinating time schedules. Mentors now include new community partners and those mentors (returnees) who wish to continue to mentor students. Because, students and mentors who participated in the first class, have shared their experiences with other students and community members, folks who wish to be mentors for this class now contact me and express their interest in being a mentor; every year, more people with disAbilities wish to be mentors for this class.

The majority of the mentors ( 21 to 68 years of age) are returnees from the $1^{\text {st }}$ and $2^{\text {nd }}$ years; for some of them, this is the $3^{\text {rd }}$ or $4^{\text {th }}$ consecutive year in mentoring students. We (the mentors and I) have become friends, colleagues and co-instructors in our combined efforts to support students in understanding disAbility and inclusion. I still like to hover over the student teams during the initial few weeks, but now it is only because I am as excited as everyone else. I have learnt that my role in the classroom is to open up space in which all of us can learn in our own time and in our own way.

In the syllabus, the requirements for the projects have become more fluid more open and are directed towards artifying (e.g. using diverse art forms to engage in social change) the pursuit of social justice in relation to disAbility and inclusion. Many people with disAbilities help each other in expressing themselves using various art forms such as photography, video, music, drama, poetry, and dance. According to Vasey (2004), disability art is both a political as well as an artistic platform that "...challenges and exposes negative images of disability, combats images of passivity and dependence, discrimination and oppression, and celebrates difference" (p. 110). The project presenta- 
tions are now 10 - 12 minutes in duration, rather than 20 - 30 minutes. The labour intensity required in developing a longer presentation has been diminished in order for students and mentors to focus more on the process of developing meaningful relationships and not on developing a product that is graded. Even though these presentations are still graded, everyone receives the same grade (a first class grade) because the process has become more important than the final product; developing relationships and having fun are central to the team's work. Project presentations have expanded beyond power point slide presentations and include such wonderful creations as paintings, poetry, rap songs, music, games, creative movement and dance and role-plays. The last day of class continues to be a celebration that includes food and drinks with friends, family and community members including health care practitioners, and diverse members of the university community.

On a personal level, I have learnt at a much deeper and more visceral level than I had prior to the class that I $A M$ my unique differences. I also have learnt that I have unique capacities for embracing difference, and as George, one of the student mentors said " $I$ see" the world from my differences. My lived experiences of disAbility reveal my existing vulnerabilities and capacity to embrace other diverse forms of ability. I believe that only by continually adding to my lived experiences and learning from others with disAbilities will I be able to expand my capacity to embrace difference and further reveal (share) my vulnerabilities with others. The cumulative experiences of this class project have greatly expanded my capacity to embrace differences and to recognize those differences as completely natural to the human experience; and have also unexpectedly created a safer place for me to share my vulnerabilities with others. I have come to know on a much richer level that until I recognize and begin to accept all of my vulnerabilities and all diversities in all situations, my capacity to inclusively embrace all disAbility will languish. This class has become a place of transition: a place of inclusivity that shares diverse abilities and vulnerabilities as well as enhanced capacities for embracing differences: a place of transition that has opened up vital spaces for personal and professional growth, for reflexive thoughts, feelings and actions.

\section{Conclusions \& Recommendations}

As the instructor, I am only one individual who is describing and sharing a collective experience of many individuals in which I was privileged to be a part of but really more from a participatory ledge of observation rather than from the perspective of a truly participatory member. I am aware that this is a privileged place for me, to be able to describe and share the experience of this collaborative class project. I also recognize that with a small qualitative project such as the one described in this paper, that the project findings are reflective of the time and place and meaningful to those who participated in it. It is my sincere hope that in describing this collaborative project and by sharing some of the voices of the students, mentors and a support person that I have captured the essence or meaning of this project in a way that will have some utility for all individuals, but particularly for pre-service social work students and practitioners, 
interdisciplinary educators, and other health care professionals.

Project recommendations include the following: continued exploration of the described pedagogical method in this project in order to support student learning outcomes in pre-service social work students, other health care pre-service students such as those in Education, Medicine, and Nursing and those students in interdisciplinary health-care service programs; and the need for further research that examines diverse disability-studies pedagogy that considers collaborative teaching methods that includes people with disAbilities. On-going collaborative pedagogical methods with persons with lived experiences of disAbility are needed in the classroom in order to assist pre-service social work students to support their understanding of the disAbility experience, and through that understanding, enhance their comfort levels in working with people with disAbilities; embracing the disability experience as an integral aspect of the human condition.

\section{Acknowledgements}

$\mathrm{RJ}$ thanks all of the community partners who so freely gave of their time and expertise to mentor and support the learning of pre-service professional social work students.

\section{References}

Allen, K. N., \& Friedman, B. D. (2010). Affective Learning: A Taxonomy for Teaching Social Work Values Journal of Social Work Values and Ethics, 7, 12 p.

Amney, V. (2014). Ensuring the Quality of the Findings of Qualitative Research: Looking for Trustworthiness Criteria. Journal of Emerging Trends in Educational Research and Policy Studies, 5, 272-281.

Banner, J. M., \& Cannon, H. C. (1999). Teaching as an Art Form-A Review of the Elements of Teaching. New Haven, CT: Yale University Press.

Bolzan, N., Heycox, K., \& Hughes, L. (2001). From Pillar to Post: Women and Social Work Studies in the 21st Century. Australian Social Work, 54, 67-79. http://dx.doi.org/10.1080/03124070108415265

Brown, H. K., Ouellette-Kuntz, H., Lysaght, R., \& Burge, P. (2011). Students' Behavioural Intentions towards Peers with Disability. Journal of Applied Research in Intellectual Disabilities, 24, 322-333. http://dx.doi.org/10.1111/j.1468-3148.2010.00616.x

Bunch, R. S., \& Hodge, S. R. (2004). Student Attitudes towards Peers with Disabilities in Inclusive and Special Education Schools. Disability \& Society, 19, 61-75. http://dx.doi.org/10.1080/0968759032000155640

Burge, P., Ouellette-Kunz, H., Issacs, B., \& Lunsky, Y. (2008). Medical Students' Views on Training in Intellectual Disabilities. Canadian Family Physician, 54, 568-571.

Drolet, J., Clark, N., \& Allen, H. (Eds.) (2012). Shifting Sites of Practice: Field Education in Canada. Toronto, ON: Pearson Canada Inc.

Dunn, P., Hanes, R., Hardie, S., \& MacDonald, J. (2006). Creating Disability Inclusion within Canadian Schools of Social Work. Journal of Social Work in Disability and Rehabilitation, 5, 1-19. http://dx.doi.org/10.1300/J198v05n01 01

Ferguson, P. M., \& Nusbaum, E. (2012). Disability Studies: What Is It and What Difference Does It Make? Research \& Practice with Persons with Severe Disabilities, 37, 70-80. http://dx.doi.org/10.2511/027494812802573530 
Friedman, B. D. (2008). How to Teach Effectively. Chicago, IL: Lyceum Books, Inc.

Hartz, M. B., \& Beal, J. R. (2000). Patients' Attitudes and Comfort Levels Regarding Medical Students' Involvement in Obstetrics-Gynecology Outpatient Clinics. Academic Medicine, 75, 1010-1014. http://dx.doi.org/10.1097/00001888-200010000-00018

Hayashi, R., \& May, G. E. (2011). The Effect of Exposure to a Professor with a Visible Disability on Students' Attitudes towards Disabilities. Journal of Social Work in Disability \& Rehabilitation, 10, 36-48. http://dx.doi.org/10.1080/1536710X.2011.546300

Hiranandani, V. (2005). Towards a Critical Theory of Disability in Social Work. Critical Social Work, 6, 1-14.

http://www1.uwindsor.ca/criticalsocialwork/towards-a-critical-theory-of-disability-in-social-w ork

Johner, R. (2013). Disability \& Poverty: Stories That Resist Attitudinal Barriers to Inclusion. Canadian Journal of Disability Studies, 2, 31-53. http://dx.doi.org/10.15353/cjds.v2i3.100

Jurkowski, E., \& Welch, P. (2002). Integrating Curriculum Content on Disability within Social Work Practice: Tools for Curriculum Building (pp. 1-12). Montpelier: The Congress of the International Association of Schools of Social Work.

Kahn, P. (2003). Teaching Tomorrow's Docs. New Mobility, 9, 45-48.

Lincoln, Y. S., \& Goya, E. G. (1985). Naturalistic Inquiry. Newbury Park, CA: Sage Publications.

Lord, J., \& Hutchison, P. (2007). Pathways to Inclusion: Building a New Story with People and Communities. Concord, ON: Captus Press.

MacDonald, J., Dunn, P., \& Hanes, R. (2003). Disability: From Curriculum to Accommodations, a Decade of Reflections. Halifax: Canadian Association of Schools of Social Work Education.

Minihan, P. M., Bradshaw, Y. S., Long, L. M., Altman, W., Perduta-Fulginiti, S., Ector, J., Foran, K. L., Johnson, L., Kahn, P., \& Sneirson, R. (2004). Teaching about Disability: Involving Patients with Disabilities as Medical Educators. Disability Studies Quarterly, 24, 1-13. http://dx.doi.org/10.18061/dsq.v24i4.883

Morris, J. (1991). Pride against Prejudice: Transforming Attitudes to Disability. London: Women's Press.

Parken, A. (2010). A Multi-Strand Approach to Promoting Equality and Human Rights in Policymaking. Policy and Politics, 38, 79-99. http://dx.doi.org/10.1332/030557309X445690

Pfeiffer, D., \& Yoshida, K. (1995). Teaching Disability Studies in Canada and the USA. Disability \& Society, 10, 475-500. http://dx.doi.org/10.1080/09687599550023462

Place, K., \& Hodge, S. R. (2001). Social Inclusion of Students with Physical Disabilities in General Physical Education: A Behavioural Analysis. Adapted Physical Activity Quarterly, 18, 389-404.

Pound, C., \& Hewitt, A. (2005). Communication Barriers: Building Access and Identity. In J. Swain, S. French, C. Barnes, \& C. Thomas (Eds.), Disabling Barriers-Enabling Environments (pp. 161-168). Thousand Oaks, California: SAGE Publications Inc.

Shannon, C. D., Schoen, B., \& Tansey, T. N. (2009). The Effect of Contact, Context, and Social Power on Undergraduate Attitudes towards Persons with Disabilities. Journal of Rehabilitation, 75, 11-18.

Silvers, A., \& Francis, L. P. (2005). Justice through Trust: Disability and the “Outlier Problem" in Social Contract Theory. Ethics, 116, 40-77. http://dx.doi.org/10.1086/454368

Stienstra, D. (2012). About Canada: Disability Rights. Manitoba: Fernwood Publishing.

Terzi, L. (2009). Vagaries of the Natural Lottery? Human Diversity, Disability, and Justice: A Capability Perspective. In K. Brownlee, \& A. Cureton (Eds.), Disability and Disadvantage (pp. 86-109). Oxford: Oxford University Press. http://dx.doi.org/10.1093/acprof:osobl/9780199234509.003.0004 
Titchkosky, T. (2007). Reading and Writing Disability Differently: The Textured Life of Embodiment. Toronto: University of Toronto Press.

Titchkosky, T. (2009). Disability Studies: The Old and the New. In T. Titchkoksy, \& R. Michalko (Eds.), Rethinking Normalcy a Disability Studies Reader (pp. 38-62). Toronto: Canadian Scholars' Press Inc.

Vasey, S. (2004). Disability Culture: The Story So Far. In J. Swain, S. French, C. Barnes, \& C. Thomas (Eds.), Disabling Barriers-Enabling Environments (pp. 106-110). London: Sage Publications Ltd.

Vishnevsky, T., \& Beanlands, H. (2004). Qualitative Research. Nursing Journal, 31, 234-238.

Wells, T. P. E., Bryon, M. A., McMullen, S. H. P., \& Birchall, M. A. (2002). Disability Teaching for Medical Students: Disabled People Contribute to Curriculum Development [Letter to the Editor]. Medical Education, 36, 788-792. http://dx.doi.org/10.1046/j.1365-2923.2002.01264 1.x

Submit or recommend next manuscript to SCIRP and we will provide best service for you:

Accepting pre-submission inquiries through Email, Facebook, LinkedIn, Twitter, etc.

A wide selection of journals (inclusive of 9 subjects, more than 200 journals)

Providing 24-hour high-quality service

User-friendly online submission system

Fair and swift peer-review system

Efficient typesetting and proofreading procedure

Display of the result of downloads and visits, as well as the number of cited articles

Maximum dissemination of your research work

Submit your manuscript at: http://papersubmission.scirp.org/

Or contact ce@scirp.org 